\title{
"Examining the effects of behavioral biases of investors on Tehran Stock Exchange efficiency using trends and consistency in firms' financial performance during 1997-2006"
}

$\begin{array}{ll} & \text { Bahman Gholami } \\ \text { DUTHORS Rahmati } & \text { Mehdi Goudarzi }\end{array}$

Bahman Gholami, Darush Rahmati and Mehdi Goudarzi (2016). Examining the

ARTICLE INFO effects of behavioral biases of investors on Tehran Stock Exchange efficiency using trends and consistency in firms' financial performance during 1997-2006. Problems and Perspectives in Management, 14(3-si), 348-355. doi:10.21511/ppm.14(3-si).2016.07

DOI http://dx.doi.org/10.21511/ppm.14(3-si).2016.07

RELEASED ON Thursday, 15 September 2016

JOURNAL

"Problems and Perspectives in Management"

FOUNDER

LLC "Consulting Publishing Company "Business Perspectives"

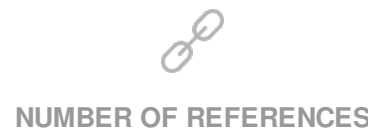

0
NUMBER OF FIGURES

0
NUMBER OF TABLES

0

(C) The author(s) 2023. This publication is an open access article. 


\title{
SECTION 2. Management in firms and organizations
}

\author{
Bahman Gholami (Iran), Darush Rahmati (Iran), Mehdi Goudarzi (Iran) \\ Examining the effects of behavioral biases of investors \\ on Tehran Stock Exchange efficiency using trends and consistency \\ in firms' financial performance during 1997-2006
}

\begin{abstract}
The present study investigates the effects of behavioral biases on the efficiency of Tehran stock exchange. In fact, these biases are the mistakes that individuals make while making financial decisions.

The methodology of this research is that firms with financial information during 1997 to 2006 that have also been active on the stock exchange have been classified based on two criterions of operating profit/per share and earnings per share, then, the return of these firms was calculated in the first period and compared to their return in the second period. Therefore, it will be clear that the companies' financial performance trend has been effective on the behavioral biases of investors and consequently on their extreme reactions towards the published information. Therefore, the process of the stock return changes can be predicted in the coming period. As a result, this hypothesis is an evidence of market inefficiency and predictability of financial behavioral theories.

On the other hand, this research does not offer sufficient and strong evidences on the effect of consistency in the financial performance process and also the presence of compatible and incompatible signs in companies' financial performance on the market predictability. Thus, in this case, it is not possible to admit the effect of behavioral biases on the predictability and thus market efficiency.
\end{abstract}

Keywords: behavioral finance, financial performance, behavioral bias, representation, conservatism.

JEL Classification: G02, G23, M41.

\section{Introduction}

One of the significant issues for financial scholars is identification behavior of investors and their movements in the financial markets, especially in the stock exchange. One of the way of identification method of these behaviors is according to behavioral finance. One of the important foundations for development of any country is its economy and of the main elements of any modern economy are the country's stock exchange and its stock market that in case of being efficient could be great help in economic growth. Certainly, human factor and capital have been and are the cornerstones of the economy. In the past, the impact of elements of capital and human force were examined almost individually, but in the past two decades, examining the effect of human factors on the capital factor has been changed into daily issue through the financial decisions since two recent decades.

Almost by 1980s, the dominant paradigm on financial issues was a new theory called Efficient Market Hypothesis (EMH), which was proposed by Jensen and Fama. In this theoretical framework, new information manifests itself quickly in the stock price and there is nowhere to earn systematic and nonconventional extra return (Fama, 1970).

(c) Bahman Gholami, Darush Rahmati, Mehdi Goudarzi, 2016.

Bahman Gholami, Department of Management, Payame Noor University, Tehran, Iran.

Darush Rahmati, Department Agricultural Economics, Payame Noor University, Tehran, Iran.

Mehdi Goudarzi, Department of Management, Payame Noor University, Tehran, Iran.
According to proponents of EMH, for market's being efficient, it is not necessary for all investors to be rational; they know its reason a result of the existence of arbitrage forces. In general, arbitrage forces compensate mistakes of irrational investors in capital market and thus help market to be more efficient (Raei and Telangy, 2004). Empirical studies of individuals' stock behavior and even market stock index led to discovery phenomena and facts that were hardly justified by EMH. These facts, which are usually called "anomalies" in financial literature, prove that some stocks systematically obtain higher average returns than other stocks while the risk factor of this stock doesn't increase to obtain such benefit. The most important anomalies can be noted as January effect, overreaction, underreaction, and momentum, which presence has been proved in many developed and some emerging markets. Nevertheless, what is important in this context is the reason of existence of these anomalies in a way that different interpretations have been offered by financial scholars for them. In behavioral finance theories, the first element is arbitrage limitations (When is the market efficient?) and the second element is cognitive psychology (How do people think?) that the second element itself is made up of two components. The first component is the investors' preferences that should be reflected in the investment process and the second part is cognitive beliefs or orientations which emergence must be prevented in investment processes (Nevins, L., 2004). 
Since cognition time and resources are limited, we cannot optimally analyze the data obtained from the environment. Therefore, human mind naturally used "rule of thumb" (Ritter, 2003). To get information on the irrational behaviors, investors refer to cognitive psychologists' research results which the behavioral biases of the investors have been studied. The meaning of bias or orientation is deviation from the correct and optimal decision-making.

In behavioral finance, behavioral biases cause investors to extrapolate the past information and trend of firms's performance more or less; therefore, unrealistic expectations about the performance and stock future return of the companies are formed among investors. Therefore, investors show extreme reactions towards the stocks of such companies, which, in turn, cause abnormal returns in future.

Three general categories of resources that cause bias in the process of thinking and decision making are: a) innovative methods, b) self-deception, c) social interactions. However, among them, two innovativeconservatism and representativeness biases can be introduced as the basic and main orientations of other biases that other biases can be introduced, to so that the other biases can be explained according to determination and explanation of these two.

Representativeness includes the willingness of individuals to classify and group objects based on their similarities and common characteristics. Tversky and Kahneman theoretically stated that when people focus on similarities, they get away from logical and rational argument. Representativeness bias shows that consistency in a string of past financial performances brings about classification and grouping companies and also the formation of biased expectations about the future performance of the companies in minds of investors.

In behavioral finance literature, representative bias causes excessive preliminary reaction against recent performance of the company and consequently leads to much higher or much lower pricing of actual price, and thus causes return reversal in the future.

Conservatism includes the unwillingness of people to review and update their thoughts and ideas about the new information. Conservative people often give more weight to base rates and less weight to the evidences and information in the samples.

In behavioral finance literature, conservatism bias leads to less reaction of the investors to new information of the companies; therefore, prices reaction is less than the size so leads to getting efficiency momentum in the future.

Nowadays, behavioral finance theories in inefficient markets have become serious replacements for efficient markets theory making testing and examining these theories a vital necessity in order to create a distinction between these two series of theories (Chan et al., 2004). Moreover, financial scholars believe that there is only one scientific way for alternative behavioral or logical theories and that is experimental studying (Barberis et al., 1998). From this perspective, this study would be useful due to evaluating the predictive power of theories of behavioral finance, as well as helping distinguish these two from each other.

Behavioral finance has the potential to be a valuable complement for neoclassical theories that are based on financial issues today. Considering that these modern theories consider psychological factors as important inputs for financial analyses, they explain many reactions in the financial markets that seem to be in conflict with traditional theories, and thus have a constructive role in avoiding decision-making mistakes and accessing to investment strategies (Fromelt, 2001).

The important deed that financial experts in the world have started to do is trying to understand and prove the decision-making and portfolio selection by professional or amateur investors. So far, such studies has been absent in financial issues set that may be due to the wrong belief that pricing asset can be done without knowing anything about the behavior of economic factors (Frankfurt et al., 2004; Shiller, 2006).

When modern financial theories didn't achieve the current progress, some prominent economists such as Adam Smith, Irving Fisher, John Maynard Keynes, and Harry Markowitz believed that the phenomena related to individual psychology affect prices.

For example, Smith analyzed the phenomenon of "superiority" in high-risk occupations. He said that this phenomenon causes the price of labor in such jobs to be lower than the actual price. Fisher wrote a book in 1930 titled "The Theory of Interest" on money illusion.

In on chapter of this book, Fisher analyzes the saving behavior of the individuals. He considered such related to issues such as self-control, prudence, and people's habits. Keynes offered his famous interpretation "Animal Spirit in the Stock Market" in 1936. Markowitz (1952) stated that people adjust their profit and loss based on reference points and this phenomenon could be used in pricing insurance (Raei and Flahpoor, 2004). All the mentioned points indicate the importance of studying behavioral and psychological sciences in financial field. To find out the importance of the behavior in financial discussions more, we refer to a financial theory definition presented by Merton. The definition that is perhaps the most correct and succinct normative definition of financial theory is as follows: 
"The base and center of financial theory is studying the behavior of economic factors in the allocation and deployment of resources regarding to time and place and in an uncertain environment. Time and uncertainty are two key factors that affect financial behavior".

As is seen, the main element of Merton's definition is behavior: "The behavior of economic factors" and "financial behavior" (Frankfurter and Mac Goun, 1996).

In general, it can be said that financial behavior is a combination of classical and financial economy with psychology and decision sciences that seeks to explain unusual phenomena observed in the financial field (Fuller, 2000).
Financial behavior represents the new approach towards financial markets and correspondingly, it is method of carrying out research in financial behavior by conducting research in structural theories from various multiple dimensions. To better understand and providing a comprehensive picture of financial behavior theory, the theoretical foundations financing or the sciences affecting finance behavior are depicted in Figure 1.

Financial behavior has two ingredients, which include arbitrage limitations (When will the market be effective?) and cognitive psychology (How do people think?) (Ritter, 2003).

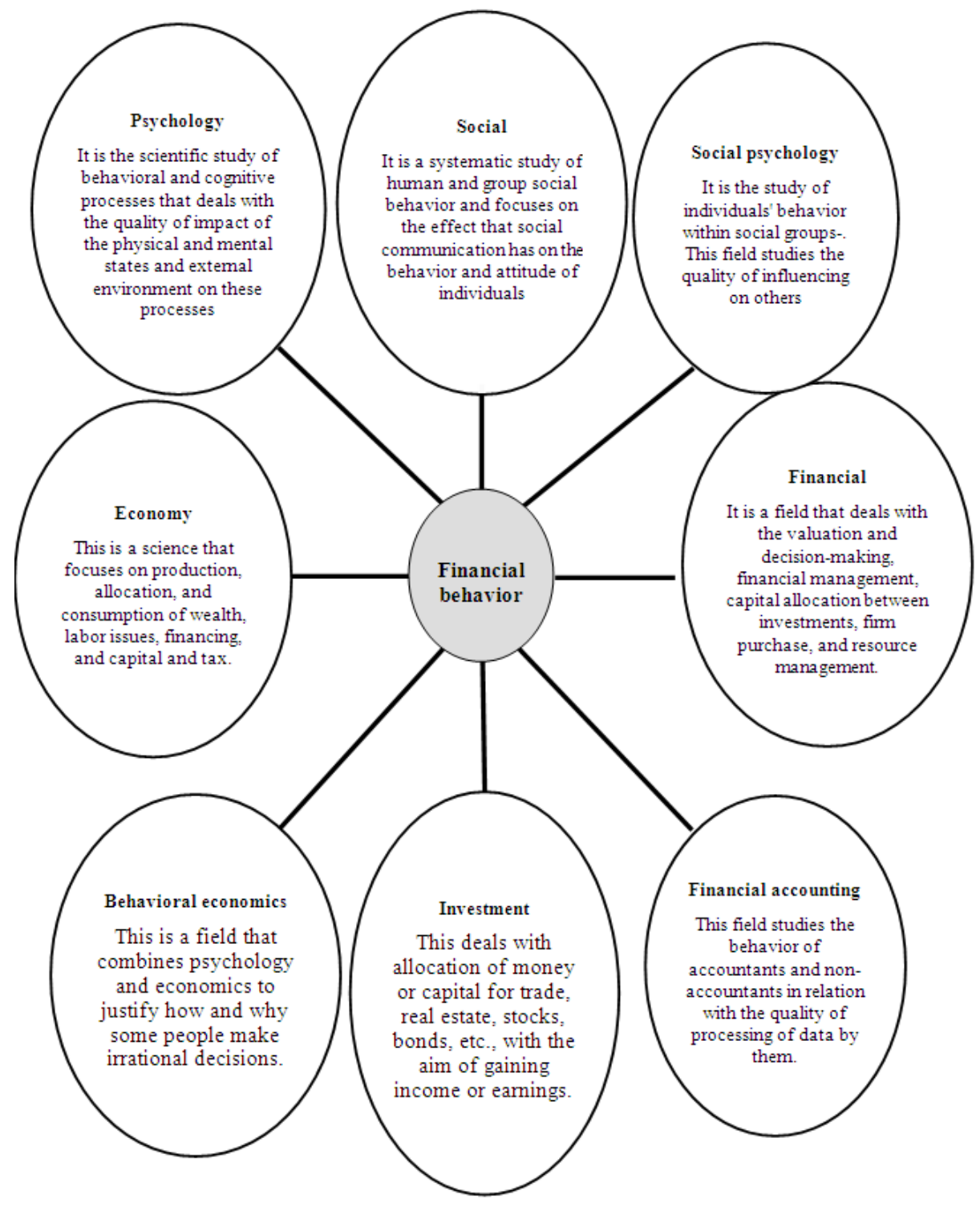

Fig. 1. The theoretical basis of financial behavior

Source: Simon and Ikyardy (2000).

In the 1970s, Ross established Arbitrage Pricing Theory (APT). The main concept in APT is the law of existing "one price", i.e., two assets (share) similar to risk and return cannot be sold at different prices. By definition, incorrect pricing of securities in a way that generates benefits without risks is called "arbitrage" (Raei and Telangi, 2004). 
Simply, under the theory of efficient prices, the prices are real, i.e., they are determined by agents that have understood Bayes' theorem and have reasonable preferences. In an efficient market "there is no free lunch" meaning no investment strategy can gain average returns without additional risk or higher average returns greater than the risk justifying that return (Barberis and Thaler, 2001).

In behavioral theories, it is assumed that arbitrage forces are limited and; therefore, cannot delete the systematic mispricing that is caused through misguided and biased information processing by investors (Shleifer and Vishny, 1997).

Financial behavior argues that some asset price specifications are interestingly interpreted as the deviation from the base value and these deviations are partly due to the presence of illogical traders.

In Table 1, the different types of people who are involved in financial decisions are provided.

Table 1. The decision makers of financial behavior

\begin{tabular}{|l|l|l|l|}
\hline \multicolumn{1}{|c|}{ Individuals } & \multicolumn{1}{|c|}{ Groups } & \multicolumn{1}{c|}{ Organizations } & \multicolumn{1}{c|}{ Markets } \\
\hline $\begin{array}{l}\text { Investor is an } \\
\text { individual who is } \\
\text { a financial } \\
\text { planner }\end{array}$ & $\begin{array}{l}\text { A group of } \\
\text { investors }\end{array}$ & $\begin{array}{l}\text { Investment } \\
\text { company }\end{array}$ & Stock market \\
\hline $\begin{array}{l}\text { Graduate } \\
\text { student }\end{array}$ & Board of directors & $\begin{array}{l}\text { Non-profit } \\
\text { organizations }\end{array}$ & Bond market \\
\hline $\begin{array}{l}\text { Member of the } \\
\text { board }\end{array}$ & Investment clubs & Agency & $\begin{array}{l}\text { International } \\
\text { markets }\end{array}$ \\
\hline & $\begin{array}{l}\text { Financial education } \\
\text { class colleges }\end{array}$ & $\begin{array}{l}\text { Student } \\
\text { associations }\end{array}$ & Futures markets \\
\hline
\end{tabular}

Source: Ricciardi and Simon (2000).

It is interesting to look up to common finance terminology. While irrational traders are often referred to as "Noise Traders", rational traders are usually called "Arbitrageurs". With a more precise expression, arbitrage is an investment strategy that provides a costfree profit without risk. For example, in Friedman's logic due to the belief that a wrongly priced asset creates an opportunity to obtain profits without risks, reasonable traders are known as Arbitrageurs. By financial behavior perspective, this belief is false, because the strategies that Friedman considers for reasonable traders are not necessarily arbitrage, and they very risky (Barberis and Thaler, 2001).

This research has been based on the study of Chang et al. (2004) that evaluated the predictive power of financial behavior in a study entitled "Studying financial behavior theories using stability and financial performance process". The aim of this study was to evaluate and test theories of efficient markets, known as the financial behavior using biased processing of companies' information by investors. They showed that many of the predictions of returns in the market are derived from extreme reactions of investors to models (i.e., trends and stability in the financial performance). They used two heuristic models, conservatism, and representativeness to conduct this study. In fact, they analyzed the relationship between past trends and their implications on future financial performance and trends. Their findings were as following: firstly, the stability in the company's performance during a period does not have great effect on future price performance. Secondly, they did not find evidence regarding to the issue that investors systematically show excessive reaction to trends in financial performance in long periods. In fact, abnormal returns in the future periods were not economic and statistically significant. Thirdly, they found evidences suggesting that investors show nonextremist reaction to yearly trends. Chang et al found evidence contrary to the pricing recommendations of financial behavior theories based on conservatism. Finally, they examined the issue to see whether the existence of signs, contrary to the previous practice or stability, bring about the predictability of return behavior. This study did not find evidences indicating that returns behavior is predictable.

\section{The history of the Stock Exchange in Iran}

The roots of establishing Stock Exchange in Iran date back to 1936. In this year, a Belgian expert called Ran Luterfeld with a Dutch expert carried out some studies and developed the foundation and constitution of the stock exchange at the request of Iran's government. At the same time, a group of experts at Melli Bank (National Bank) studied the issue and prepared a comprehensive report on the details of the formation of the Stock Exchange in 1936 (Davani, 2005).

In short, the activity periods of Tehran Stock Exchange can be divided into four periods: the first period (1967-1978), the second period (1979-1988), the third period (1989-2004) and the fourth period (2005-until now).

The number of companies listed on the stock exchange has increased from 422 in 2004 to 435 companies at the end of 2007.

\section{Research hypotheses}

The main hypothesis: behavioral finance theories have the ability to predict market.

2.1. Sub-hypotheses. First hypothesis: companies will experience reverse performance trend after long-term period of extreme performance. $H_{0}$ and $H_{1}$ hypotheses are as follows:

$$
\left\{\begin{array}{l}
H_{1}: \bar{R}_{H 1}-\bar{R}_{H 2}>0 \\
H_{0}: \bar{R}_{H 1}-\bar{R}_{H 2} \leq 0
\end{array}\right. \text {. }
$$


The second hypothesis: companies with extreme and stable performance will experience greater reverse performance trend compared to companies with extreme and unstable performance. $H_{0}$ and $H_{1}$ hypotheses are as follows:

$$
\left\{\begin{array}{l}
H_{1}:\left(\bar{R}_{H C 1}-\bar{R}_{H C 2}\right)-\left(\bar{R}_{H I 1}-\bar{R}_{H I 2}\right)>0 \\
H_{0}:\left(\bar{R}_{H C 1}-\bar{R}_{H C 2}\right)-\left(\bar{R}_{H I 1}-\bar{R}_{H I 2}\right) \leq 0
\end{array} .\right.
$$

The third hypothesis: Following a series of incompatible signs of companies with past extreme and stable performance will experience greater reversal of stock returns trend compared to companies with extreme and unstable performance.

$H_{0}$ and $H_{1}$ hypotheses are as follows:

$$
\left\{\begin{array}{l}
H_{1}:\left(\bar{R}_{H C D 1}-\bar{R}_{H C D 2}\right)-\left(\bar{R}_{H I D 1}-\bar{R}_{H I D 2}\right)>0 \\
H_{0}:\left(\bar{R}_{H C D 1}-\bar{R}_{H C D 2}\right)-\left(\bar{R}_{H I D 1}-\bar{R}_{H I D 2}\right) \leq 0
\end{array}\right. \text {. }
$$

2.2. Research domain. Time domain of the research is from 1997 to 2006 and subject includes testing the effects of behavioral biases of the investors on the performance of Tehran Stock Exchange through trends and stability in the companies' financial performance.

\section{Research methodology}

Regarding to the purpose, this study is applicable. Regarding to data collection, this study is descriptivesurvey. The target population is all companies listed on the stock exchange that have been active in 1997 and have remained active during these ten years of the study. Due to limitations of this study such as the necessity for sufficient time for the formation of the behavior of investors, as well as having a sufficient volume of companies for multiple classifications, sampling has been used in the present study purposive. As purpose of this study is to compare two dependent groups in the first hypothesis and compare the two independent groups in the second and third hypotheses, nonparametric test that evaluates the status of two dependent groups, Wilcoxon test, is better than others. Therefore, in this study, non-parametric Wilcoxon test is used to test the first hypothesis. To test the two independent samples, which are different regarding to the number of members of each (the second and third hypotheses), non-parametric MannWhitney $U$ test is the most appropriate option.

\section{Hypothesis testing using a classification based on sales per share of companies with high growth}

After calculating the variables using the Excel software, SPSS software was used to examine the relationship between them and the research hypotheses were tested.
The first hypothesis: after a period of high or low and long-term financial performance, the companies will experience reverse performance.

$\mathrm{H}_{0}$ and $\mathrm{H}_{1}$ hypotheses are as follows:

$\left\{\begin{array}{l}H_{1}: \bar{R}_{H 1}-\bar{R}_{H 2}>0 \\ H_{0}: \bar{R}_{H 1}-\bar{R}_{H 2} \leq 0\end{array}\right.$.

$\mathrm{H}_{0}$ hypothesis states that stock returns for firms with high growth in the first period is less than the amount in the second period, while the $\mathrm{H}_{1}$ hypothesis states that stock returns for firms with high growth in the first period is greater than the amount in the second period. The results of the analyses are given in Table (3-4): (confidence level of $95 \%$ is considered in this study).

Table 2. The results of first hypothesis analysis for companies with high growth

\begin{tabular}{|c|c|}
\hline Asym. Sig (2-tailed) & Z calculated \\
\hline 0.000 & -4.276 \\
\hline
\end{tabular}

In this table, $Z$ value and its statistics coverage is calculated. If the absolute value of $\mathrm{Z}$ calculated is greater than 1.96 , we consider mean difference in the two positions and reject the hypothesis $H_{0}$.

From the amount of Asymp. Sig (2-tailed) it can be concluded. If the resulting number is less than $5 \%$, the difference in the two positions and rejecting the $H_{0}$ hypothesis can be concluded. The absolute value of $\mathrm{Z}$ calculated is 4.276 that is more than 1.96 and reflects the difference from two situations (before and after). The amount of Asym. Sig (2-tailed) is equal to zero and, as it is smaller than $5 \%$, it again reflects the differences from two situations. Thus, with $95 \%$ level of confidence $H_{0}$ hypothesis is rejected and $H_{1}$ denoting the reversal trend of performance in the next period is confirmed.

The second hypothesis: companies with high, low, and stable performance will experience greater reversal of performance compared to companies with high, low, and unstable performance.

$\mathrm{H}_{0}$ and $\mathrm{H}_{1}$ hypotheses are as follows:

$$
\left\{\begin{array}{l}
H_{1}:\left(\bar{R}_{H C 1}-\bar{R}_{H C 2}\right)-\left(\bar{R}_{H I 1}-\bar{R}_{H I 2}\right)>0 \\
H_{0}:\left(\bar{R}_{H C 1}-\bar{R}_{H C 2}\right)-\left(\bar{R}_{H I 1}-\bar{R}_{H I 2}\right) \leq 0
\end{array}\right. \text {. }
$$

Table 3. The results of the second hypothesis for companies with high growth

\begin{tabular}{|c|c|}
\hline Asym.Sig (2-tailed) & Z calculated \\
\hline 0.006 & -2.767 \\
\hline
\end{tabular}

The absolute value of $\mathrm{Z}$ calculated is 2.767 that is greater than 1.96 and represents the difference from two situations (before and after). The amount of Asym. 
Sig (2-tailed) is 0.006 . Since it is less than $5 \%$, still reflects the differences in the two states. Thus, with $95 \%$ level of confidence $\mathrm{H}_{0}$ hypothesis is rejected and $H_{1}$ denoting the reversal trend of performance in the next period is confirmed.

The third hypothesis: following a series of incompatible signs, companies with past high, low, and stable performance will experience greater reversal of performance compared to companies with extreme and unstable performance.

$\mathrm{H}_{0}$ and $\mathrm{H}_{1}$ hypotheses are as follows:

$\left\{\begin{array}{l}H_{1}:\left(\bar{R}_{H C D 1}-\bar{R}_{H C D 2}\right)-\left(\bar{R}_{H I D 1}-\bar{R}_{H I D 2}\right)>0 \\ H_{0}:\left(\bar{R}_{H C D 1}-\bar{R}_{H C D 2}\right)-\left(\bar{R}_{H I D 1}-\bar{R}_{H I D 2}\right) \leq 0\end{array}\right.$.

Table 4. The results for the third hypothesis of highgrowth companies

\begin{tabular}{|c|c|}
\hline Asym. Sig (2-tailed) & Z calculated \\
\hline 0.014 & -2.452 \\
\hline
\end{tabular}

The absolute value of $\mathrm{z}$ is calculated as -2.452 that is more than 1.96 and reflects the difference from two situations (before and after). The amount of Asym.Sig (2-tailed) is equal to 0.014 and as it is smaller than 5\%, it again reflects the differences from two situations. Thus, with $95 \%$ level of confidence $H_{0}$ hypothesis is rejected and $\mathrm{H}_{1}$ denoting the reversal trend of performance in the next period is confirmed.

4.1. Companies with low growth. The first hypothesis: after a period of high, low, and long-term financial performance, the companies will experience reverse performance.

$H_{0}$ and $H_{1}$ hypotheses are as follows:

$\left\{\begin{array}{l}H_{1}: \bar{R}_{L 1}-\bar{R}_{L 2}<0 \\ H_{0}: \bar{R}_{L 1}-\bar{R}_{L 2} \geq 0\end{array}\right.$.

Table 5. The results of testing the first hypotheses for companies with low growth

\begin{tabular}{|c|c|}
\hline Asym. Sig (2-tailed) & Z calculated \\
\hline 0.000 & -3.693 \\
\hline
\end{tabular}

Thus, with $95 \%$ level of confidence, $H_{0}$ is rejected and $\mathrm{H}_{1}$ hypothesis denoting the reversal trend of performance in the next period will be accepted.

The second hypothesis: companies with low, high, and stable performance will experience greater reversal of performance compared to companies with low, high, and unstable performance.

$H_{0}$ and $H_{1}$ hypotheses are as follows:

$$
\left\{\begin{array}{l}
H_{1}:\left(\bar{R}_{L C 1}-\bar{R}_{L C 2}\right)-\left(\bar{R}_{L I 1}-\bar{R}_{L I 2}\right)<0 \\
H_{0}:\left(\bar{R}_{L C 1}-\bar{R}_{L C 2}\right)-\left(\bar{R}_{L I 1}-\bar{R}_{L I 2}\right) \geq 0
\end{array} .\right.
$$

Table 6. The results of the second hypothesis for companies with low growth

\begin{tabular}{|c|c|}
\hline Asym. Sig (2-tailed) & Z calculated \\
\hline 0.380 & -0.877 \\
\hline
\end{tabular}

Thus, with $95 \%$ level of confidence $H_{0}$ hypothesis is accepted and $H_{1}$ hypothesis denoting the reversal trend of performance in the next period is rejected.

The third hypothesis: following a series of signs incompatible with the previous period, companies with past low, high, and stable financial performance will experience greater reversal of performance compared to companies with low, high, band unstable performance.

$H_{0}$ and $H_{1}$ hypotheses are as follows:

$$
\left\{\begin{array}{l}
H_{1}:\left(\bar{R}_{L C D 1}-\bar{R}_{L C D 2}\right)-\left(\bar{R}_{L I D 1}-\bar{R}_{L I D 2}\right)<0 \\
H_{0}:\left(\bar{R}_{L C D 1}-\bar{R}_{L C D 2}\right)-\left(\bar{R}_{L I D 1}-\bar{R}_{L I D 2}\right) \geq 0
\end{array} .\right.
$$

Table 7. The results of the third hypothesis analysis for companies with low growth

\begin{tabular}{|c|c|}
\hline Asym. Sig (2-tailed) & Z calculated \\
\hline 0.280 & -1.280 \\
\hline
\end{tabular}

Thus, with $95 \%$ level of confidence, $H_{0}$ is accepted and $\mathrm{H}_{1}$ denoting the reversal trend of performance in the next period is rejected.

Testing hypotheses using classification based on operating profit (loss),

Companies with high growth

The first hypothesis: after a period of high or low and long-term financial performance, companies will experience reverse performance trend.

Hypotheses $H_{0}$ and $H_{1}$ are as follows:

$$
\left\{\begin{array}{l}
H_{1}: \bar{R}_{H 1}-\bar{R}_{H 2}>0 \\
H_{0}: \bar{R}_{H 1}-\bar{R}_{H 2} \leq 0
\end{array} .\right.
$$

Table 8 . The results of analyzing the first hypothesis for companies with high growth

\begin{tabular}{|c|c|}
\hline Asym. Sig (2-tailed) & Z calculated \\
\hline 000.0 & -6.135 \\
\hline
\end{tabular}

Thus, with $95 \%$ level of confidence $H_{0}$ hypothesis is rejected and $H_{1}$ denoting the reversal trend of performance in the next period is confirmed.

The second hypothesis: companies with low, high, and stable financial performance will experience greater reversal of performance compared to companies with low, high, and unstable financial performance.

$H_{0}$ and $H_{1}$ hypotheses are as follows: 


$$
\left\{\begin{array}{l}
H_{1}:\left(\bar{R}_{H C 1}-\bar{R}_{H C 2}\right)-\left(\bar{R}_{H I 1}-\bar{R}_{H I 2}\right)>0 \\
H_{0}:\left(\bar{R}_{H C 1}-\bar{R}_{H C 2}\right)-\left(\bar{R}_{H I 1}-\bar{R}_{H I 2}\right) \leq 0
\end{array} .\right.
$$

Table 9. The results of second hypothesis analysis for companies with high growth

\begin{tabular}{|c|c|}
\hline Asym. Sig (2-tailed) & Z calculated \\
\hline 0.50 & -1.957 \\
\hline
\end{tabular}

Thus, with $95 \%$ level of confidence $H_{0}$ hypothesis is accepted and $H_{1}$ hypothesis denoting the reversal trend of performance in the next period is rejected.

The third hypothesis: after a period of incompatible financial performance with previous period, companies which past financial performance was low, high, and stable will experience greater reversal of returns compared to companies with low, high, and unstable performance.

$H_{0}$ and $H_{1}$ hypotheses are as follows:

$\left\{\begin{array}{l}H_{1}:\left(\bar{R}_{H C D 1}-\bar{R}_{H C D 2}\right)-\left(\bar{R}_{H I D 1}-\bar{R}_{H I D 2}\right)>0 \\ H_{0}:\left(\bar{R}_{H C D 1}-\bar{R}_{H C D 2}\right)-\left(\bar{R}_{H I D 1}-\bar{R}_{H I D 2}\right) \leq 0\end{array}\right.$.

Table 10. The results of the analysis of the third hypothesis for companies with high growth

\begin{tabular}{|c|c|}
\hline Asym. Sig (2-tailed) & Z calculated \\
\hline 0.353 & -0.930 \\
\hline
\end{tabular}

Thus, with $95 \%$ level of confidence, $H_{0}$ is accepted and $H_{1}$ denoting the reversal trend of performance in the next period is rejected.

4.2. Companies with low growth. First hypothesis: after a period of high or low and long-term financial performance, companies will experience reversed performance trend.

$H_{0}$ and $H_{1}$ hypotheses are as follows:

$\left\{\begin{array}{l}H_{1}: \bar{R}_{L 1}-\bar{R}_{L 2}<0 \\ H_{0}: \bar{R}_{L 1}-\bar{R}_{L 2} \geq 0\end{array}\right.$.

Table 11. The results of the analysis of the first hypotheses for companies with low growth

\begin{tabular}{|c|c|}
\hline Asym. Sig (2-tailed) & Z calculated \\
\hline 0.002 & -3.145 \\
\hline
\end{tabular}

Thus, with $95 \%$ level of confidence, $H_{0}$ is rejected and $H_{1}$ hypothesis denoting the reversal trend of performance in the next period is accepted.

The second hypothesis: companies with low, high, and stable financial performance will experience greater reversal of returns compared to companies with low or high but unstable performance.

$H_{0}$ and $H_{1}$ hypotheses are as following:
$\left\{\begin{array}{l}H_{1}:\left(\bar{R}_{L C 1}-\bar{R}_{L C 2}\right)-\left(\bar{R}_{L I 1}-\bar{R}_{L I 2}\right)<0 \\ H_{0}:\left(\bar{R}_{L C 1}-\bar{R}_{L C 2}\right)-\left(\bar{R}_{L I 1}-\bar{R}_{L I 2}\right) \geq 0\end{array}\right.$.

Table 12. The results of the analysis of the second hypothesis for companies with low growth

\begin{tabular}{|c|c|}
\hline Asym. Sig (2-tailed) & Z calculated \\
\hline 0.033 & -2.133 \\
\hline
\end{tabular}

Thus, with $95 \%$ level of confidence, $H_{0}$ is rejected and $H_{1}$ hypothesis denoting the reversal trend of performance in the next period is accepted.

The third hypothesis: Following a series of incompatible financial performance with the previous period, companies with past low, high, and stable financial performance will experience greater reversal of performance compared to companies with low or high but unstable performance.

$H_{0}$ and $H_{1}$ hypotheses are as follows:

$\left\{\begin{array}{l}H_{1}:\left(\bar{R}_{L C D 1}-\bar{R}_{L C D 2}\right)-\left(\bar{R}_{L I D 1}-\bar{R}_{L I D 2}\right)<0 \\ H_{0}:\left(\bar{R}_{L C D 1}-\bar{R}_{L C D 2}\right)-\left(\bar{R}_{L I D 1}-\bar{R}_{L I D 2}\right) \geq 0\end{array}\right.$.

Table 13. The results of the analysis of the third hypothesis for companies with low growth

\begin{tabular}{|c|c|}
\hline Asym. Sig (2-tailed) & Z calculated \\
\hline 0.309 & -1.017 \\
\hline
\end{tabular}

Thus, with $95 \%$ level of confidence, $H_{0}$ is accepted and $H_{1}$ denoting the reversal trend of performance in the next period is rejected.

\section{Research results}

5.1. The first hypothesis: after the period of high or low and long-term financial performance, companies will experience reversal trend of performance.

Confirmation of the first hypothesis reflects the effect of representativeness behavioral bias on the behavior of investors and their overreaction to receive financial stock information from this type of companies, then, they over-evaluate the shares of these companies (more than the actual value). As a result, after the passage of time and adjustment of value of the stock market, these companies' experience reversed returns.

5.2. The second hypothesis: companies with low, high, and stable financial performance will experience greater reversed performance compared to companies with low, high, and unstable financial performance.

Confirmation of the second hypothesis indicates that existence of stability in the financial performance of companies will increase the behavioral bias's effects on investors' behavior and thereby increase the overreaction of investors to these companies, and after the passage of time and 
realization of the mistake by the investors, prices are adjusted to their real value, thus, the efficiency of these companies will be reversed.

5.3. The third hypothesis: after a period of incompatible financial performance with previous period, the companies whose financial performance was high, low, and stable, will experience more severe adversed performance trends compared to the companies which financial performance was high, low, and consistent.

Confirmation of the third hypothesis indicates that investors in companies with high, low, and stable growth under the influence of representativeness behavioral bias show less reaction than what is needed to these incompatible signs; therefore, with the passage of time and adjustment of prices towards these signals, the returns will be reversed. On the other hand, investors in companies with high, low, and unstable growth show less-than-required reaction under the influence of conservatism behavioral bias towards incompatible signs. As a result, after adjustment of prices towards these signs, they will experience less inverted yield.

Generally, it can be seen that the company's financial performance is effective on the formation of behavioral biases in the investors; therefore, their extreme reactions were published towards the information. Therefore, the trend of the change of stock return in coming period can be predicted. As a result, this hypothesis is an evidence of market inefficiency and the prediction ability of behavioral financial theories.
On the other hand, this research does not offer sufficient and strong evidences on the effect of consistency in the financial performance process and the presence of compatible and incompatible signs in companies' financial performance on the ability to predict market. Thus, in this case, it is not possible to acknowledge the effect of behavioral biases on the predictability and, thus, market efficiency.

\section{Conclusion}

1. Based on the type of variable that investors use to classify, they have different ideas about corporate growth. Therefore, we recommend investors to avoid herding movements, meaning to comply, buy, and sell shares of the companies, because on the basis of personal classification and representatives that a person has from the companies, they attempts to buy or sell stock.

2. Investors are recommended to avoid representativeness bias and never buy a company's stock, just because its previous performance has been high and does not avoid buying the stock of a company just as its earlier is low.

3. Researchers are recommended to use earnings and dividend per share variables for the classification of companies.

4. Researchers are recommended to examine, control, or neutralize the effect of the float in their studies, so that the results are more objective.

5. Future researchers are recommended to determine the time required for the reversal of the firm's financial performance in their goals, because each time series is reversed, so it is better to identify the process reversal time.

\section{References}

1. Barberis, N. and Thaler, R. (2001). A Survey of Behavioral Finance. Handbook of the Economics of Finance, North-Holland, Amsterdam.

2. Barberis, N., Shleifer, A. and Vishny, R. (1998). A model of investor sentiment, Journal of Financial Economics, 49, pp. 307-343.

3. Chan, S.W., Frankel, R. and Kothari, S.P. (2004). Behavioral finance theories using trends and consistency in financial performance, Journal of Accounting and Economics, 38, pp. 38-50.

4. Davani, G. (2005). Stock Exchange, stock and how to price the stock. $4^{\text {th }}$ edition. Tehran: Nokhostin Publications.

5. Fama, E.F. (1970). Efficient Capital Markets: A Review of Theory and Empirical Work, Journal of Finance, 25 (2), pp. 383-417.

6. Frankfurter, G.M. and McGoum, E.G. (1996). Toward Finance with Meaning, the Methodology of Finance: what is and what is can be. JAI press Inc.

7. Frankfurter, M.G., McGoun, G.E. and Allen, E.D. (2004). The prescriptive turn in behavioral finance, Journal of Socio-Economics, 33, pp. 449-468.

8. Fromlet, H. (2001). Behavioral finance theory and practical application, Business Economics, 36 (3), pp. 63-69.

9. Fuller, R. (2000). Behavioral Finance and the Source of Alpha, Fuller \& Thaler Asset Management.

10. Nevins, Dan. (2004). Goals-based Investing: Integrating Traditional and Behavioral Finance, The Journal of Wealth Management, 6 (4), pp. 1-24.

11. Raei, R. and Fallahpour, S. (2004). Behavioral finance, a different approach in the field of finance, Financial Research, 18 (Winter), pp, 77-106.

12. Raei, R. and Telangy, A. (2004). Advanced investment management. SAMT Publications.

13. Ricciardi, V. and Simon, H. (2000). What is Behavioral Finance? The Business, Education and Technology Journal, 2 (1), pp. 26-34.

14. Ritter, R.J. (2003). Behavioral finance, Journal of Pacific-Basin Finance, 21, pp. 429-437.

15. Shiller J. Robert. (2006). Tools for Financial Innovation: Neoclassical versus Behavioral Finance, The Financial Review, 41, pp. 1-8.

16. Shleifer, A. and Vishny, R. (1997). The limits to arbitrage, Journal of Finance, 52 (1), pp. 35-55. 